\title{
OBSERVATIONS ON THE LATE RESULTS OF THE MCMURRAY OSTEOTOMY FOR OSTEOARTHRITIS OF THE HIP *
}

\author{
Thomas King and Brendan Dooley, Melbourne, Australia
}

From St Vincent's Hospital, Melbourne

This report deals with the results after two to twenty years of forty-five osteotomies for primary or secondary osteoarthritis. Although the cases are not consecutive, the report includes all those patients who could be traced in 1960. For example, of twenty-six patients who had osteotomies performed between 1935 and 1939, only two could be traced.

\section{MATERIAL}

Forty-five patients who between 1938 and 1958 were subjected to femoral osteotomy for degenerative arthritis of the hip were traced. Patients who had undergone osteotomy for

TABLE I

Age at Time of Osteotomy (Forty-five patients)

\begin{tabular}{|cc|}
\hline $\begin{array}{c}\text { Age at time of } \\
\text { osteotomy } \\
\text { (years) }\end{array}$ & $\begin{array}{c}\text { Number of } \\
\text { patients }\end{array}$ \\
\hline $21-30$ & 3 \\
$31-40$ & 4 \\
$41-50$ & 7 \\
$51-60$ & 15 \\
over 60 & 16 \\
\hline
\end{tabular}

TABLE II

TYPE OF OSTEOARTHRITIS (Forty-five patients)

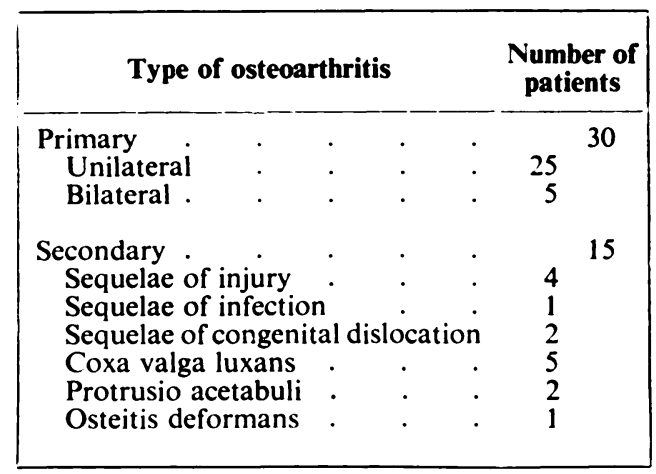

TABLE III

Period of Observation after Operation (Forty-five patients)

\begin{tabular}{|c|c|}
\hline $\begin{array}{c}\text { Period of observation } \\
\text { (years) }\end{array}$ & $\begin{array}{c}\text { Number of } \\
\text { patients }\end{array}$ \\
\hline $2-5$ & 15 \\
$6-10$ & 8 \\
$11-15$ & 12 \\
$16-20$ & 10 \\
\hline
\end{tabular}

unreduced congenital dislocation or for ununited fracture were excluded. There were twentytwo men and twenty-three women. The average age was fifty-four years (Table I). In five patients the disease affected both hips, and there were two bilateral and three unilateral operations. Thirty hips were classed as having " primary" osteoarthritis and fifteen as having

* Paper read at the Australian Orthopaedic Association Mecting in Sydney in August 1960. 
“ secondary" osteoarthritis (Table II). In eleven post-operative immobilisation was by traction and in thirty-four by internal fixation. In most cases the period of observation was ten years or more (Table III).

\section{SELECTION OF PATIENTS}

Patients with primary senile osteoarthritis affecting both hips and swiftly crippling them were considered unsuitable. But when progress was slower and the disorder mainly unilateral those patients with unendurable pain and severe restriction of walking were carefully selected for operation. We used to deny operation to this group because ischaemia from arteriosclerosis was held to be the cause of the arthritis. Now, however, angiography has shown that there is an adequate circulation in the normal femoral head in old age (Trueta and Harrison 1953) and has suggested that there is hyperaemia in primary osteoarthritis (Harrison, Schajowicz and Trueta 1953). Venographs have also demonstrated venous stasis in the head and neck (Hulth 1958).

In the secondary form of osteoarthritis the cartilage has been damaged not by age but by disease or injury, such as a reduced dislocation (Figs. 11 and 12). The patients are younger, their bone is denser and their prognosis is better. Coxa valga luxans or dysplasia was included because of its similarity to an osteoarthritic hip with a pathological subluxation.

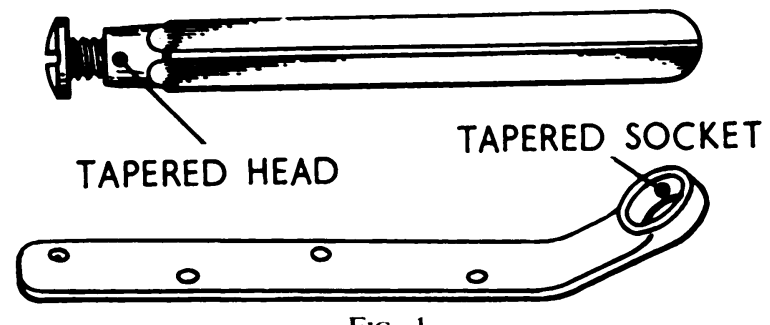

FiG. 1

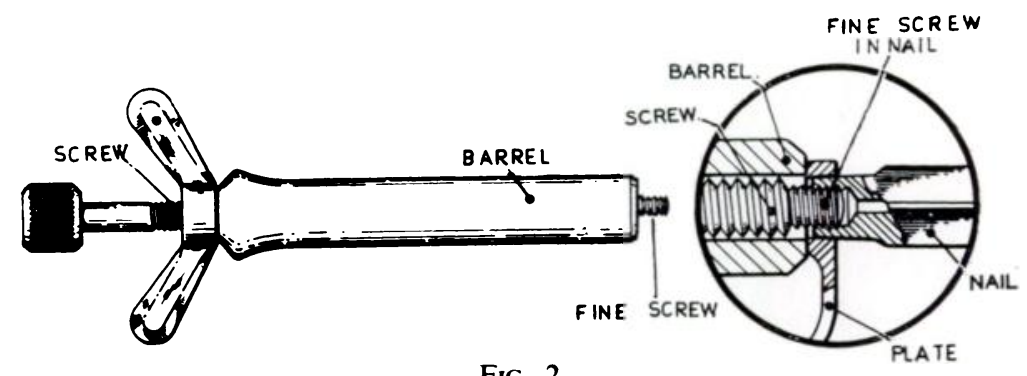

FiG. 2

Special instruments. Figure 1-The nail with tapered head, and the plate with socket tapered to fit. Figure 2-Instrument for pulling the nail into the tapered socket. Another special instrument (not illustrated) is needed for separating the nail and plate.

\section{TECHNIQUE OF OPERATION}

After 1944 internal fixation was used exclusively, because it gave complete control over the adduction of the upper fragment that is regarded as the key to the operation (Blount 1943, Wardle 1955, Shepherd 1960). The use of internal fixation also broadened the indications for operation to include older patients for whom immobilisation in bed for three months or more had the special danger of thrombo-embolic complications (Merle d'Aubigné, Tubiana and Duparc 1955).

The object of operation is to reproduce the old operation for correcting a severe adduction deformity, but because this deformity is seldom present, it has to be created by adducting the 


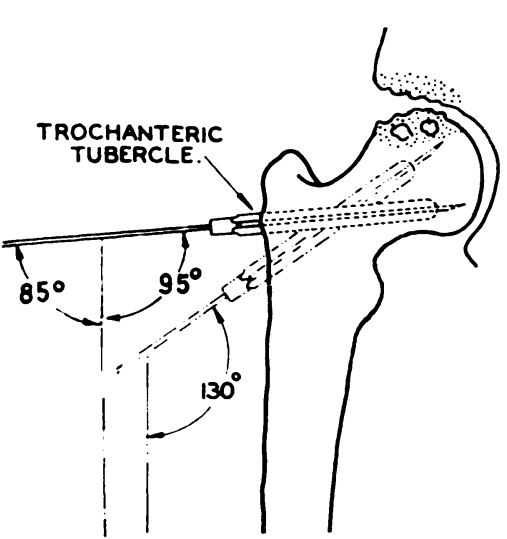

FIG. 3

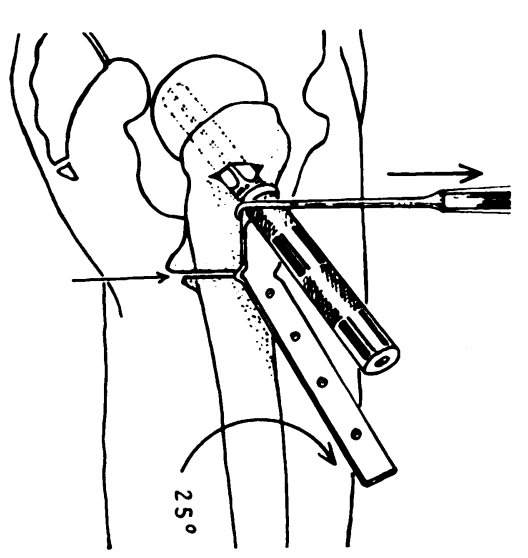

FIG. 5

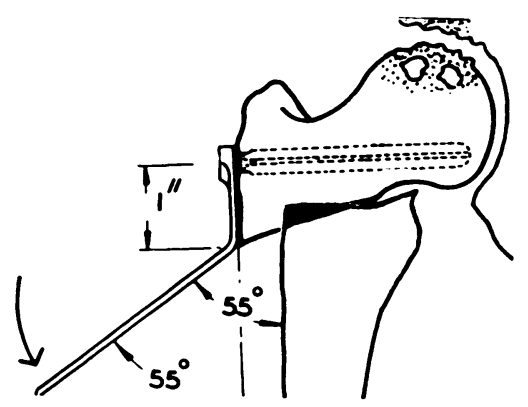

FIG. 7

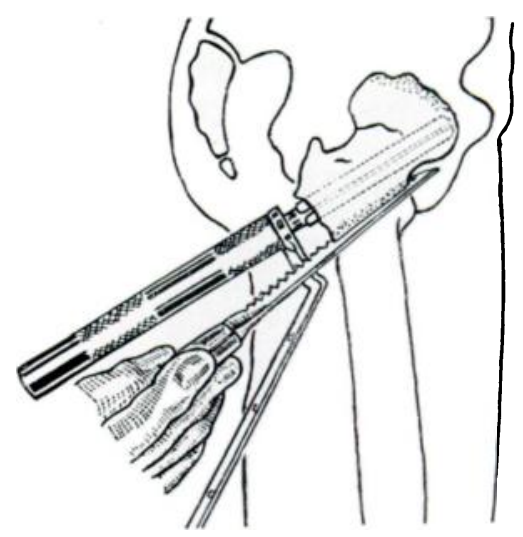

FiG. 4

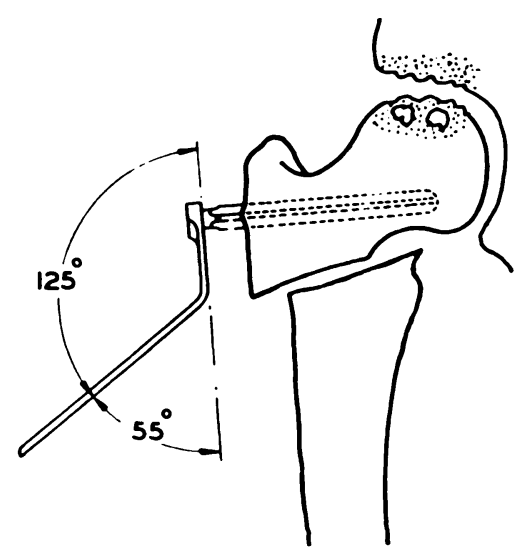

Fig. 6

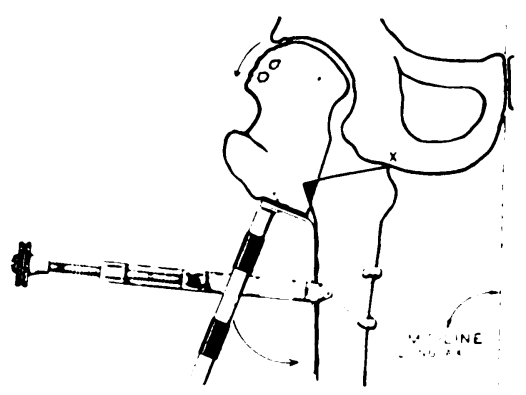

FiG. 8

Technique of operation. Figure 3-The correct angle of insertion of the nail. Note that it is directed towards the lower part of the head. Incorrect angle of insertion (130 degrees) is also shown. Figure 4-Division of femur. The femur is laterally rotated and is divided with a metacarpal saw. Note the oblique line of bone section. Figure 5-With the femur medially rotated 25 degrees the proximal fragment is hooked forward into neutral position before the plate is clamped. Figure 6-The position of the nail and plate during osteotomy. Note short arm of plate parallel with lateral surface of proximal fragment. Figure 7The nail and plate driven home. The short arm of the plate rests on the femur and the adduction of the proximal fragment and displacement of the distal fragment are now controlled by movement of the plate. Figure 8-Proximal fragment adducted and shaft displaced medially until it impinges against the pelvis. Note the leverage on the plate by means of the handle, and the clamp used to hold the plate on to the femur. The two legs are brought together in the mid-line to avoid genu valgum later. 
upper fragment by a handle screwed into the nail (Figs. 1 to 8). Although before operation the range of adduction and medial rotation may be small or negligible, adduction of the upper fragment is almost always easily obtained with the disappearance of muscle spasm in the

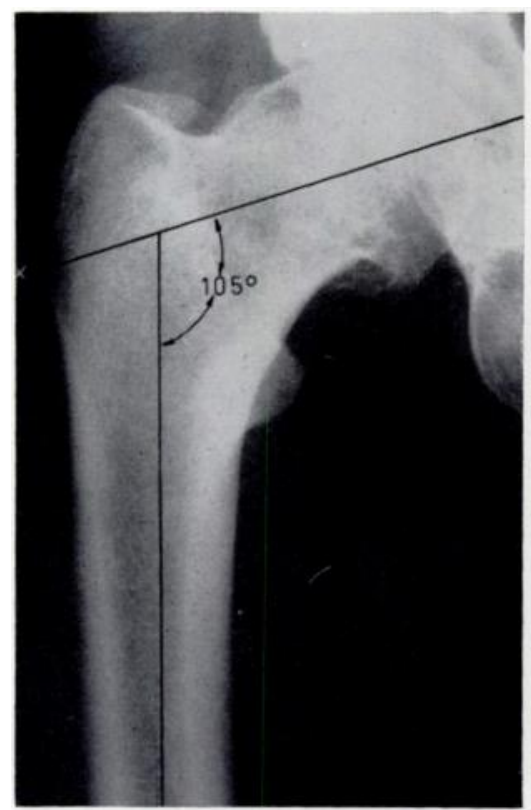

FiG. 9

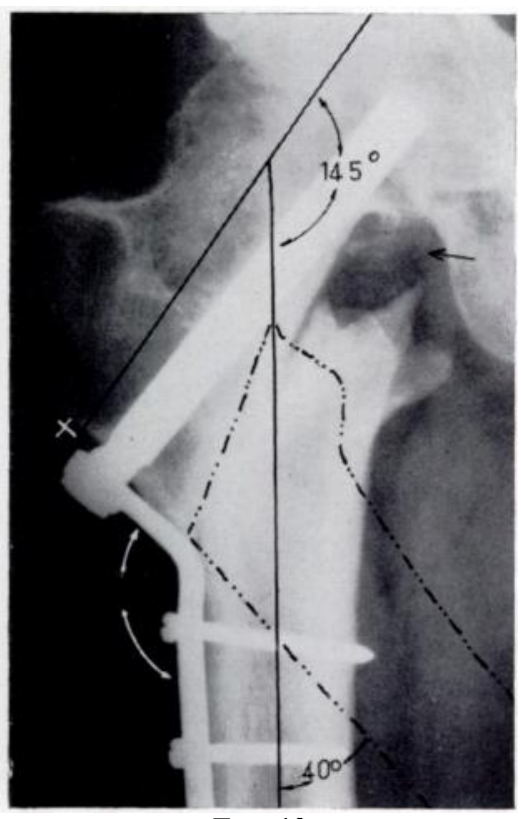

FIG. 10

Adduction of upper fragment and abutment of lower fragment against pelvis achieved despite pre-operative coxa vara and inferior osteophyte. Figure 9-Primary osteoarthritis in a man of fifty-three. Note inferior osteophyte. Adduction (15 degrees) and flexion (90 degrees) were the only movements possible. Figure 10-After osteotomy: 40 degrees adduction easily obtained in anaesthetised patient. Medial displacement of lower fragment easily achieved.

anaesthetised patient, and especially after the femur has been divided (Figs. 9 and 10). To a lesser degree this holds for medial rotation before osteotomy. In only one patient was it necessary to divide a large inferior capital osteophyte before adduction could be obtained.

TABLE IV

Duration of Relief of Pain after Osteotomy (Thirty-two patients)

(Twenty-two of these under observation and still pain-free between 1957 and 1960)

\begin{tabular}{|c|c|}
\hline $\begin{array}{c}\text { Duration of relief of pain } \\
\text { (years) }\end{array}$ & $\begin{array}{c}\text { Number of } \\
\text { patients }\end{array}$ \\
\hline $1-3$ & 7 \\
$4-7$ & 5 \\
$9-11$ & 7 \\
$12-14$ & 7 \\
$17-19$ & 6 \\
\hline
\end{tabular}

TABLE V

Radiological Changes after Operation (Thirty-seven hips)

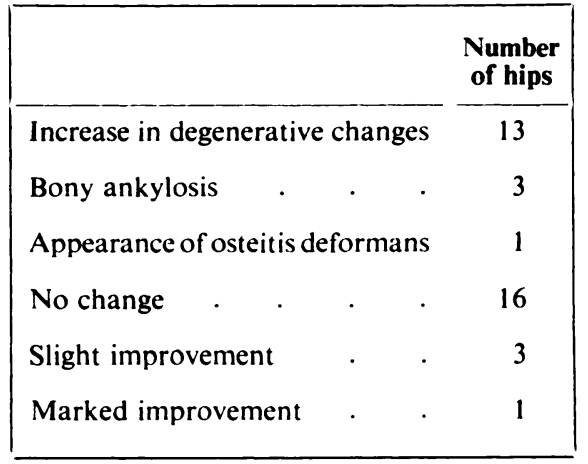

RESULTS

Relief of pain-Twenty patients obtained complete relief of pain soon after operation and stayed free of pain for ten years or more. Two of these later had recurrences of pain, and 
two more had simply a return of aching. Thirteen patients-one of whom died two years after operation-obtained complete relief of pain for periods of less than ten years, but eight of these are still under review and pain free (Table IV): four were lost sight of after three to

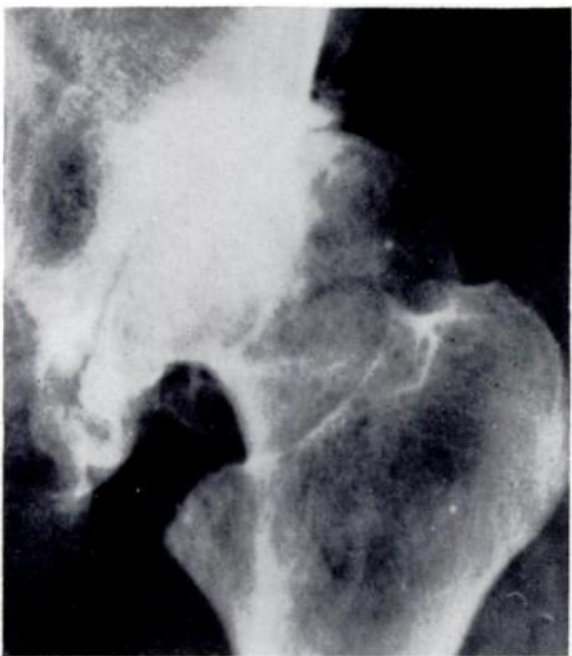

Fig. 11

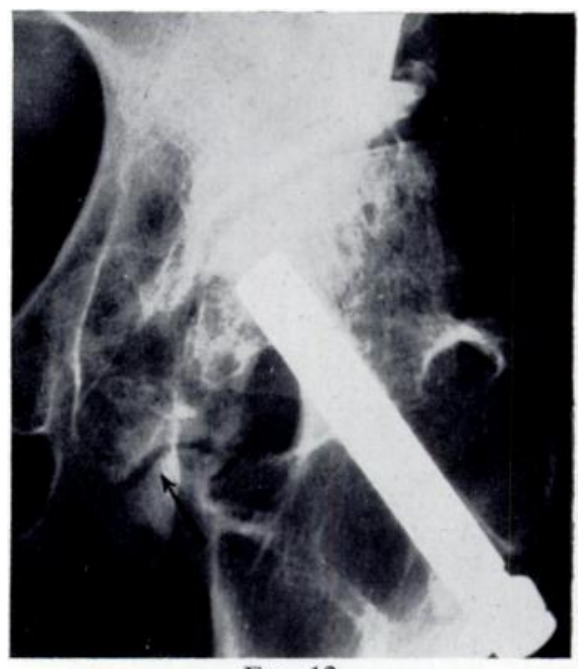

FIG, 12

Regression of radiological changes after operation. Figure 11-Degenerative arthritis in hip of woman of fifty-two, following congenital dislocation and subsequent treatment. Figure 12-Ten years after osteotomy: increase of " joint space," diminution in size of "cysts." Note the abutment of the femur against the pelvis and the consequent pseudarthrosis. The patient had no pain and could walk any distance; the ranges of flexion and of lateral and medial rotation were 45 degrees.

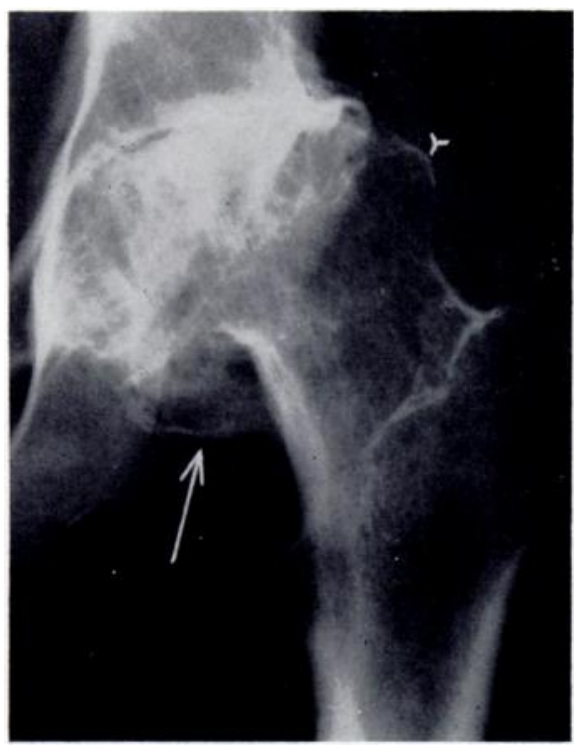

FIG. 13

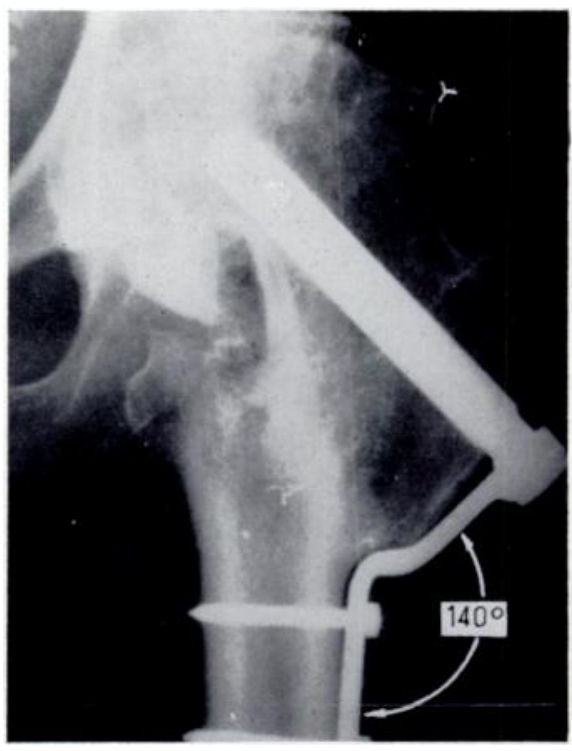

FIG. 14

"Pelvic support" from displacement of the distal fragment. Figure 13-Degenerative arthritis in hip of woman of thirty-eight, following upper femoral epiphysiolysis. Note the large anteroinferior osteophyte. There was fixed adduction. Figure 14-After osteotomy with internal fixation: the upper fragment has been adducted $\mathbf{4 0}$ degrees and the lower fragment has been displaced medially to abut against the pelvis. Note how the rotation of the upper fragment has carried the "pressure area" of the head away from the acetabulum.

ten years. (Three patients with ankylosis are not included in Table IV as being relieved of pain by osteotomy.) Eight patients obtained improvement and one had no improvement at all

vol. 44 B, No. 3, AUgust 1962 
(Table IV). Altogether five patients experienced delayed subsidence of pain, relief occurring in two as long as five years after operation and in the other three, two years after operation. Radiological changes after operation-Radiographs of thirty-seven hips, twenty-three of them taken more than ten years after operation, were available for examination. Thirteen of these showed increase of degenerative changes, three showed actual bony ankylosis, and one showed the features of osteitis deformans. Sixteen showed no evidence of change in the degenerative process; three showed slight improvement and in one there was marked improvement (Table $\mathrm{V}$, Figs. 11 and 12).

Relation of radiological change to relief of pain-All four patients with radiological evidence of improvement had stayed pain free up to the time of review. More than half of those whose radiographs showed no change were free of pain at the time of review, and the same held for those with radiological evidence of further degeneration.

Range of movement-As a rule movements stayed much the same as they were before operation, tending to become reduced over the years. Some patients obtained a moderate increase in the range of movement, especially that of medial rotation. The range of flexion was usually well preserved, but that of adduction was regularly diminished.

Complications-There were no serious thrombo-embolic incidents.

Non-union-Failure of union at the site of osteotomy occurred three times-once when external and twice when internal splintage was used. In the first patient the fragments remained ununited and bony ankylosis of the hip followed. In the other two the fragments united after bone grafting, but in one of these the hip became ankylosed.

Infection-Wound infection occurred in four patients, but in only one of these did it go on to septic arthritis and ankylosis. Two of them have occasional trouble from flare-up of infection but are free from the original pain.

\section{DISCUSSION}

Mechanism of relief of pain-The reasons originally put forward for the relief of pain by osteotomy were that correction of the adduction deformity removed the abnormal thrust through the diseased joint (Malkin 1936), and that weight was transferred or redistributed below the inferior acetabular margin (Hey Groves 1933) (Figs. 13 and 14). McMurray (1935) proposed osteotomy for painful osteoarthritis even in the absence of adduction deformity, but aimed at obtaining adduction of the proximal fragment together with medial displacement of the femoral shaft. The present report is of course based on those principles.

The finding that simple osteotomy without displacement relieved pain (McFarland 1954, Adam and Spence 1958, Campbell and Jackson 1955) cast doubt on the original hypothesis. There is, however, a possibility of error in such observations. For example, displacement is not in fact possible if the upper fragment is strongly adducted either as a result of the disease or by manipulation during operation. In either instance the femoral shaft is close to the inferior acetabular margin, just as it is in osteotomy with maximum displacement in which there has been little or no adduction of the upper fragment. The greater the adduction of the upper fragment the less displacement is necessary for the complete pelvic block. But any adduction of the upper fragment after osteotomy, even when there has been insufficient displacement to create a pelvic support or block, brings weight bearing closer to the mid-line. This might be an important factor in those cases where relief of pain has been reported despite little or no displacement. Other factors could be prolonged immobilisation by external splinting, and vascular decompression (Hulth 1958), though the latter would cease to be significant after bony union had taken place. Another factor is the effect of adduction of the proximal fragment in rotating laterally the pressure area of the femoral head so that it is no longer congruous with the "pressure area" in the upper margin of the diseased but still weight-bearing acetabulum (Fig. 14) (Harrison and colleagues 1953). Lloyd-Roberts (1955) thought that the relief of pain 
might be related to relaxation of the capsule, by adduction, lateral rotation and flexion of the proximal fragment.

Regeneration of joint after osteotomy-Indications of arrest of the degenerative process and even of regenerative changes have sometimes been observed after osteotomy. Such indications are broadening of the joint space; rounding of the head; healing of cysts and restoration of areas of destruction of cancellous bone (Blount 1957, Adam and Spence 1958, Robins and Piggot 1960, Nissen 1960). The significance of the apparent increase in the joint space has been questioned (Arden 1957, Robins and Piggot 1960). These improved radiographic appearances were rare in this series, and were certainly not sufficiently striking to justify osteotomy at an earlier stage of the disease.

Conclusions from present evidence-In elderly patients with severe pain and much restriction of activity osteotomy offers a good chance of relieving pain, with little danger of vascular complications. It is more certain in its results than is arthroplasty, and, as Burrows, Murley and Shephard (1955) say, it may be regarded as "the most reliable of all operations for osteoarthritis of the hip." Although in younger patients arthrodesis still is the better long term procedure, it is often rejected by them. Hence even in this group of patients osteotomy still has an important place.

We wish to thank Miss E. Binns, Records Officer at St Vincent's Hospital, for her help.

\section{REFERENCES}

AdAm, A., and SPENCE, A. J. (1958): Intertrochanteric Osteotomy for Osteoarthritis of the Hip. Journal of Bone and Joint Surgery, 40-B, 219.

Arden, G. P. (1957): Variations in Joint Space of the Hip as Shown Radiographically. Journal of Bone and Joint Surgery, 39-B, 750.

Blount, W. P. (1943): Blade-Plate Internal Fixation for High Femoral Osteotomies. Journal of Bone and Joint Surgery, 25, 319.

Blount, W. P. (1957): Personal communication.

Burrows, H. J., Murley, A. H. G., and Shephard, E. (1955): Displacement Osteotomy for Osteoarthritis of the Hip. Results more than Ten Years Later. Journal of Bone and Joint Surgery, 37-B, 168.

CampBell, J. P., and JACKson, J. P. (1955): The Treatment of Osteoarthritis of the Hip by Osteotomy. Journal of Bone and Joint Surgery, 37-B, 167

Groves, E. W. Hey (1933): Surgical Treatment of Osteo-arthritis of the Hip. British Medical Journal, $1,3$.

Harrison, M. H. M., Schajowicz, F., and Trueta, J. (1953): Osteoarthritis of the Hip: A Study of the Nature and Evolution of the Disease. Journal of Bone and Joint Surgery, 35-B, 598.

Hulth, A. (1958): Circulatory Disturbances in Osteoarthritis of the Hip: A Venographic Study. Acta Orthopaedica Scandinavica, 28, 81.

Lloyd-Roberts, G. C. (1955): Osteoarthritis of the Hip. Journal of Bone and Joint Surgery, 37-B, 8.

McFarland, B. (1954): My Present Attitude to Osteo-Arthritis of the Hip. Journal of Bone and Joint Surgery, 36-A, 476.

McMurray, T. P. (1935): Osteo-arthritis of the Hip-Joint. British Journal of Surgery, 22, 716.

Malkin, S. A. S. (1936): Femoral Osteotomy in Treatment of Osteo-arthritis of the Hip. British Medical Journal, i, 304.

Merle d’Aubigné, R., Tubiana, R., and Duparc, J. (1955): Les complications thrombo-emboliques en chirurgie orthopédique et en traumatologie. Leur fréquence et leur prévention. Mémoires de l'Académie de Chirurgie, 81, 1,011.

Nissen, K. I. (1960): The Arrest of Primary Osteoarthritis of the Hip. Journal of Bone and Joint Surgery, 42-B, 423.

Robins, R. H. C., and Piggot, J. (1960): McMurray Osteotomy. With a Note on the "Regeneration" of Articular Cartilage. Journal of Bone and Joint Surgery, 42-B, 480.

SHePherd, M. M. (1960): A Further Review of the Results of Operations on the Hip Joint. Journal of Bone and Joint Surgery, 42-B, 177.

Trueta, J., and Harrison, M. H. M. (1953): The Normal Vascular Anatomy of the Femoral Head in Adult Man. Journal of Bone and Joint Surger!, 35-B, 442.

WardLe, E. N. (1955): Displacement Osteotomy of the Upper End of the Femur. Journal of Bone and Joint Surgery, 37-B, 568.

vol. 44 B, No. 3, AUGUST 1962 